DOI: https://doi.org/10.24164/prosiding.v3i1.23

\title{
ISLAM DAN ENTITAS KEBUDAYAAN DALAM RITUAL PEMBACAAN KIDUNG RAHAYU DI DESA CIKEDUNGLOR INDRAMAYU
}

\author{
Islam and Cultural Entities in the Kidung Rahayu Reading Ritual \\ in the Village of Cikedunglor Indramayu
}

\author{
Wahyu Iryana
}

STKIP Pangeran Dharma Kusuma Segeran

Jalan Raya KH. Hasyim Asy’ari No.1 Segeran Kidul Juntinyuat

E-mail:wahyu_iryana@yahoo.com

\begin{abstract}
Indramayu people are known to have a distinctive, and unique culture. Indramayu's cultural identity is considered as a description of the generalization of Indramayu's individual and communal ethnic identity in behavior and life. Their lives at the place of origin and overseas often carry over from their regional culture. The Context of the Song of Rahayu Tradition by Sunan Kalijaga, for example by the community of Cikedunglor in addition as an effort to preserve culture is also applied as an effort to expel disturbances from evil spirits is realized by the use of various hymn survivors. The data used are Rahayu hymns in the form of text and oral that are still and have been used. The research method begins with heuristics, source criticism, interpretation and historiography. The results of the study are First, the structure of the text which consists of the analysis of syntactic formulas, variations of diction and language style as well as themes or isotopes. Second, the lexicon reference in Rahayu's song. Third, the mirror of Rahayu's life concept of the Cikpapanlor Indramayu Regency is described by the sentences and the use of the lexicon in Rahayu's song. There are a number of sentences that reflect the concept of the life of the Indramayu people of Cikayu in the appearance of the layaicon wardaya (sanubarinya), rinaksa (guarded), sarira hayu (safe), kinarya (used), pinayunga (umbrella), ingideran (surrounded) more dominant than other lexicons.
\end{abstract}

Keywords: Culture, Kidung, Indramayu.

\begin{abstract}
Abstrak
Masyarakat Indramayu dikenal memiliki budaya yang khas, dan unik. Identitas budaya Indramayu dianggap sebagai deskripsi dari generalisasi jatidiri individual maupun komunal etnik Indramayu dalam berperilaku dan berkehidupan. Kehidupan mereka di tempat asal maupun di perantauan kerapkali terbawa budaya asal daerah. Konteks Tradisi Kidung Rahayu karya Sunan Kalijaga misalnya oleh masyarakat Cikedunglor selain sebagai upaya pelestarian budaya juga diaplikasikan sebagai upaya mengusir gangguan dari roh-roh jahat diwujudkan dengan penggunaan berbagai kidung selamat. Data yang digunakan adalah kidung Rahayu berbentuk teks dan lisan yang masih dan pernah digunakan. Metode penelitian diawali dengan heuristik, kritik sumber, intepretasi dan Historiografi. Hasil dari penelitian adalah Pertama, struktur teks yang terdiri atas analisis formula sintaksis, ragam diksi dan gaya bahasa serta tema atau isotopi. Kedua, referensi leksikon dalam kidung Rahayu Ketiga, cermin konsep hidup rahayu orang Cikedunglor Kabupaten Indramayu dideskripsikan oleh kalimat-kalimat dan penggunaan leksikon dalam kidung Rahayu. Ada beberapa kalimat yang mencerminkan konsep hidup rahayu orang Indramayu di Cikedunglor kemunculan leksikon wardaya
\end{abstract}


(sanubarinya), rinaksa (dijaga), sarira hayu (selamat), kinarya (digunakan), pinayunga (dipayungi), ingideran (dikelilingi) lebih dominan dibandingkan leksikon lainnya.

Kata kunci: Budaya, Kidung, Indramayu.

\section{PENDAHULUAN}

$\mathrm{K}$ idung adalah sejenis pupuh, guguritan yang memiliki makna mendalam biasanya ditembangkan pada malam hari oleh pujangga, maha guru, atau pun seorang ibu yang sedang memberi wejangan kepada anaknya. Kidung bumi segandu merupakan pepeling hidup masyarakat CirebonDermayon dengan memakai varian tafsir makna lahiriah, berisi tentang falsafah hidup, dawuh Kanjeng Sunan Gunung Jati. Konsep ajaran kidung bumi segandu bisa dipadukan dengan nadhomanmaca patekah (macapat), membaca surat Al-fatihah sebagai purwa (awalan) melantunkannya. Kidung bumi segandu kini diadopsi oleh para seniman sebagai produk budaya. Kidung kemudian diejawantahkan oleh para sinden dalam pertunjukan wayang, selametan kelahiran, khitanan, dan pernikahan yang dilantunkan dengan gitar dan seruling.

Islam seolah mengikuti sifat air, mengisi pos pos di setiap jiwa jaman. Kendati pun begitu, kekentalan dan kelekatan keberislaman setiap individu maupun kelompok dalam suatau jaman tidak selalu mencerminkan nilai-nilai normatif ajaran yang sesuai dengan tuntunan keislaman. Kondisi semacam ini apabila dicermati lebih dalam bisa disebabkan oleh penetrasi ajaran Islam yang dipandang relatif berhasil ke dalam komunitas, termasuk juga komunitas masyarakat etnik di wilayah Indramayu dalam realitasnya berinteraksi (tepatnya, to be interplay) dengan kompleksitas elemenelemen sosiokultural.

Oleh karena itu, pemahaman dan penafsiran atas ajaran Islam normatif pada warga Indramayu pada perkembangannya berjalan seiring dengan kontekstualitas konkret budayanya yang ternyata sangat dipengaruhi jika tidak dikatakan bermuatan heretical oleh lingkup lokalitas dan serial waktu yang membentuknya (Rahman, 1994: 141). Dalam perwujudannya, keberagamaan etnisitas komunal itu ternyata menampakkan diri dalam bentuk local tradition di mana Islam sebagai great tradition (ajaran dan praksis normatif) membentuk konsepsi tentang realitas yang mengakomodasi kenyataan sosiokultural masyarakatnya atau komunitas yang dibentuknya itu (Azra, 1999: 12). Kehadiran dan keberadaan Islam ke dalam suatu entitas sosial budaya telah menjadi "gerakan aktual-kultural" yang mengakomodasi dialog dalam/dengan beragam segmentasi kehidupan sehingga wajah Islam normatif dimungkinkan mengalami perubahan walaupun pada sisi periferalnya.

Kenyataan demikian tampak pada konsepsi yang teraktualisasikan dalam bentuk-bentuk perilaku pada budaya orang-orang Indramayu yang ternyata mengalami perubahan format jika tidak disebut bias atau deviasi dari norma asalnya. Perilaku demikian dapat diungkapkan, antara lain: sebagian pedagang Indramayu berjualan tidak sesuai dengan spesifikasi yang diucapkan (dijanjikan), tindakan premanisme, penghormatan berlebihan atau kultus individual pada figur kiai, ketersinggungan yang sering berujung atau dipahami sebagai penistaan harga diri, perbuatan heretikal, temperamental, reaktif, keras kepala, dan penyelesaian konflik 
melalui tindak kekerasan fisik (biasa disebut carok).

Contoh-contoh tersebut tidak saja menggambarkan bahwa keberagamaan sebagian masyarakat Indramayu "berseberangan" dengan ajaran normatif, moral, dan perenial Islam, melainkan berdampak juga pada munculnya stigma dan stereotipikal etnik secara komunal dan kultural dalam realitas praksis yang berjangkauan luas. Menghadapi kenyataan demikian, kearifan pandangan budaya benarbenar perlu dihadirkan sebagai bagian dari upaya solutif atas beragam problema tersebut.

Dalam kerangka itulah artikel ini disusun dengan maksud untuk mengupas tentang budaya masyarakat Indramayu pada sisi praksis religiusitasnya. Kajian ini diupayakan berorientasi pada pola pandang yang relatif utuh dan holistik dengan menghindari penilaian maupun justifikasi simplistik atau dikotomik yang kemudian hanya akan menghasilkan pandangan "hitam-putih" atau otentisitasheretikal yang sulit memberi pemahaman dan penjelasan tentang kompleksitas seting dan konteks pada realitas kehidupan etnisitas mereka. Fokus artikel akan membincangankan terkait relasi Islam dan Budaya dengan narasi tradisi kidung rahayu di Cikedunglor Indramayu.

\section{PEMBAHASAN}

Masyarakat Indramayu dikenal memiliki budaya yang khas, unik, stereotipikal, dan stigmatik. Penggunaan istilah khas menunjuk pada pengertian bahwa entitas etnik Indramayu memiliki kekhususankultural yang tidak serupa dengan etnografi komunitas etnik lain (Hasan Alwi, 2001: 563). Kekhususan kultural itu tampak antara lain pada ketaatan, ketundukan, dan kepasrahan mereka secara hierarkis kepada empat figur utama dalam berkehidupan, lebih-lebih dalam praksis keberagamaan. Keempat figur itu adalah Bupa, Ema/Mimi, Guru, Kuwu/pemrentah (Ayah, Ibu, Guru, dan Pemimpin pemerintahan). Kepada figurfigur utama itulah kepatuhan hierarkis orangorang Indramayu menampakkan wujudnya dalam kehidupan sosial budaya mereka (Wiyata, 2003: 1).

Kepatuhan atau ketaatan kepada Ayah dan Ibu (Bapa lan Ema) sebagai orangtua kandung atau nasabiyah sudah jelas, tegas, dan diakui keniscayaannya. Secara kultural ketaatan dan ketundukan seseorang kepada kedua orangtuanya adalah mutlak. Jika tidak, ucapan atau sebutan kedurhakanlah ditimpakan kepadanya oleh lingkungan sosiokultural masyarakatnya. Bahkan, dalam konteks budaya mana pun kepatuhan anak kepada kedua orangtuanya menjadi kemestian secara mutlak, tidak dapat dinegosiasikan, maupun diganggu gugat. Yang mungkin berbeda, hanyalah cara dan bentuk dalam memanifestasikannya. Kepatuhan mutlak itu tidak terkendala oleh apa pun, sebagai kelaziman yang ditopang oleh faktor genealogis. Konsekuensi lanjutannya relatif dapat dipastikan bahwa jika pada saat ini seseorang (anak) patuh kepada orangtuanya maka pada saatnya nanti dia ketika menjadi orangtua akan ditaati pula oleh anak-anaknya. Itulah salah satu bentuk pewarisan nilai-nilai kultural yang terdiseminasi. Siklus secara kontinu dan sinambung itu kiranya akan berulang dan berkelanjutan dalam kondisi normal, wajar, dan alamiah, kecuali kalau pewarisan nilainilai kepatuhan itu mengalami keterputusan yang disebabkan oleh berbagai kondisi, faktor, atau peristiwa luarbiasa. 
Kepatuhan orang-orang Indramayu kepada figur guru berposisi pada levelhierarkis selanjutnya. Penggunaan dan penyebutan istilah guru menunjuk dan menekankan pada pengertian Kiai-pengasuh pondok pesantren atau sekurang-kurangnya Ustadz pada "sekolah-sekolah aliyah." Peran dan fungsi guru lebih ditekankan pada konteks moralitas yang dipertalikan dengan kehidupan eskatologis terutama dalam aspek ketenteraman dan penyelamatan diri dari beban atau derita di alam kehidupan akhirat (morality and sacred world). Oleh karena itu, ketaatan orang-orang Indramayu kepada figur guru menjadi penanda khas budaya mereka yang mungkin tidak perlu diragukan lagi keabsahannya.

Siklus generatif tentang kepatuhan orang Indramayu (sebagai murid) kepada figur guru ternyata tidak dengan sendirinya dapat terwujud sebagaimana ketaatan anak kepada figur I dan II, ayah dan ibunya. Kondisi itu terjadi karena tidak semua orang Indramayu mempunyai kesempatan untuk menjadi figur guru. Kendati pun terdapat anggapan-prediktif bahwa figur guru sangat mungkin diraih oleh murid karena aspek genealogis namun dalam realitasnya tidak dapat dipastikan bahwa setiap murid akan menjadi guru, mengikuti jejak orangtuanya. Oleh karenanya, makna kultural yang dapat ditangkap adalah bahwa bagi orang Indramayu belum cukup tersedia ruang dan kesempatan yang leluasa untuk mengubah statusnya menjadi orang yang senantiasa harus berperilaku patuh, tunduk, dan pasrah.

Kepatuhan orang Indramayu kepada figur Kuwu/pemrentah (pemimpin pemerintahan) menempati posisi hierarkis keempat. Figur Kuwu/pemrentah dicapai oleh seseorang dari mana pun etnik asalnya bukan karena faktor genealogis melainkan karena keberhasilan prestasi dalam meraih status. Dalam realitasnya, tidak semua orang Indramayu diperkirakan mampu atau berkesempatan untuk mencapai posisi sebagai Kuwu/pemrentah, kecuali 3 atau 4 orang (sebagai Bupati di Indramayu) dalam 5 hingga 10 tahun sekali. Itu pun baru terlaksana ketika diterbitkan kebijakan nasional berupa Undang-Undang tentang Otonomi Daerah, tahun 1999 yang silam.

Oleh karena itu, kesempatan untuk menempati figur Kuwu/pemrentah pun dalam realitas praksisnya merupakan kondisi langka yang relatif sulit diraih oleh orang Indramayu. Dalam konteks itulah dapat dinyatakan bahwa sepanjang hidup orangorang Indramayu masih tetap dalam posisi yang senantiasa harus patuh. Begitulah posisi subordinatif-hegemonik yang menimpa para individu dalam entitas etnik Indramayu.

Deskripsi tentang kepatuhan orangorang Indramayu kepada empat figur utama tersebut sesungguhnya dapat dirunut standar referensinya pada sisi religiusitas budayanya. Sebagai pulau yang berpenghuni mayoritas ( \pm 95-99\%) muslim, Indramayu menampakkan ciri khas keberislamannya, khususnya dalam aktualisasi ketaatan kepada ajaran normatif agamanya (Wiyata, 2002: 42). Kepatuhan kepada kedua orangtua merupakan tuntunan Rasulullah SAW walaupun urutan hierarkisnya mendahulukan Ibu (Ema) kemudia Ayah (Bapak). Rasulullah menyebut ketaatan anak kepada Ibunya berlipat 3 daripada Ayahnya. Selain itu juga dinyatakan bahwa keridhaan orangtua "menjadi dasar" keridhaan Tuhan. Oleh karena secara normatif-religius derajat Ibu 3 kali lebih tinggi daripada Ayah maka seharusnya produk ketaatan orang Indramayu kepada ajaran normatif Islam melahirkan budaya yang memosisikan Ibu 
pada hierarki tertinggi. Dalam kenyataannya, tidak demikian. Kendati pun begitu, secara kultural dapat dimengerti mengapa hierarki Ayah diposisikan lebih tinggi dari Ibu. Posisi Ayah dalam sosiokultural masyarakat etnik Indramayu memegang kendali dan wewenang penuh lembaga keluarga sebagai sosok yang diberi amanah untuk bertanggung jawab dalam semua kebutuhan rumah tangganya, di antaranya: pemenuhan keperluan ekonomik, pendidikan, kesehatan, dan keamanan seluruh anggota keluarga, termasuh di dalamnya Sang Ibu sebagai anggota dalam "kepemimpinan" lelaki.

Di sisi lain, kepatuhan kultural orang Indramayu kepada Guru (Kiai/Ustadz) maupun kepada pemimpin pemerintahan karena peran dan jasa mereka itu dipan dang bermanfaat dan bermakna bagi survivalitas entitas etnik Indramayu. Guru berjasa dalam mencerahkan pola pikir dan perilaku komunal murid untuk memperoleh kesejahteraan hidup di dunia dan keselamatan mendiami negeri akhirat kelak. Kontribusi mereka dipandang sangat bermakna dan berjasa besar karena telah memberi bekal untuk survivalitas hidup di alam dunia dan keselamatan akhirat pascakehidupan dunia. Sedangkan pemimpin pemerintahan berjasa dalam mengatur ketertiban kehidupan publik melalui penyediaan iklim dan kesempatan bekerja, mengembangkan kesempatan bidang ekonomik, mengakomodasi kebebasan beribadat, memelihara suasana aman, dan membangun kebersamaan atau keberdayaan secara partisipatif. Dalam dimensi religiusitas, sebutan figur Kuwu/pemrentah dalam perspektif etnik Indramayu dipersamakan dengan istilah ulil amri yang sama-sama wajib untuk dipatuhi.

Persoalan yang paling mendasar sesungguhnya terletak padapemaknaan kultural tentang kepatuhan dalam konteks subordinasi, hegemoni, eksploitasi, dan berposisi kalah sepanjang hidup. Pemaknaan tersebut perlu diletakkan dalam posisi yang berkeadilan dan proporsional. Jika kepatuhan hierarkis kepada figur I dan II tidak ada masalah karena terbentang luas untuk memperoleh dan mengubahnya secara siklis maka upaya untak mengubah kepatuhan hierarkis pada figur III dan IV dapat ditempuh melalui kerja keras dan optimisme disertai bekal pengetahuan yang sangat memadai.

Ungkapan budaya Indramayu: mon kerras pa-akerres (jika mampu dan kompeten untuk berkompetisi maka harus wibawa, kharismatik, dan efektif layaknya sebilah keris) kiranya dapat mengilhami para individu entitas etnik Indramayu untuk meraih keberhasilan dan ketenteraman dalam menjalani kehidupan yang berdaya di dunia maupun di akhirat. Naskah kidung yang menjadi objek penelitian ini adalah kidung Rahayu yang ditembangkan secara menyeluruh. Adapun salah satu contoh kidung Rahayu sebagai berikut:

Ana kidung rumeksa ing wengi

Teguh rahayu luputa ing lara

luputa saking bilahi kabéh

jim sétan datan purun

paneluhan tan ana wani

Miwah saking panggawé ala gunaning wong luput geni atemahan tirta maling adoh tan ngarah ing mami guna duduk pan sirna

\section{Sakéhing lara pan samya balik}

Sakéh ngama pan sami mirunda

Welas asih panduluné

Sakehing braja luput

Kadi kapuk tibaning wesi

Sakehing wisa tawa 
Sato galak pada tutut

Kayu ahéng lemah miring songing landak guwaning wong miring Myang saking pakipukaning merak

Pagupakaning warak sakalir Nadyan arca myang segara asat Temahan rahayu kabéh Apan dadia sarira hayu Ingideran kang widadari Rineksa ing malékat Lan sagung para rasul Pinayungan ing Hyang Suksma Ati Adam uteku baginda Esis Pangucapku Nabi Musa

Pan napasku nabi Ngisa linuwih Nabi Yakub pamiyarsa ning wang Dawud suwaraku mangké Nabi brahim nyawaku Nabi Sleman kasektén mami Nabi Yusuf rupaning wang Idris ing rambutku Baginda Ngali kuliting wang Abubakar getih daging Ngumar singgih Bebalung baginda ngusman

Sungsum sun Patimah kang linuwih Siti aminah bayuning angga Ayub ing ususku mangké Nabi Nuh ing jejantung

Nabi Yunus otot mami

Nétraku ya Muhamad

Pamuluku Rasul

Pinayungan Adam Kawa Sampun pepek sakatahéng para nabi Pan dadia salira tunggal

Wijil sawiji mulane dumadi Sampun pencar dados saisinéng jagat Kasamadan déning daté Kang amaca kang angrungu Kang anurat miwah kang nyimpeni Dadi rahayuning badan Lamon winacakna ning toya Kinarya aduse wong lara gelis mari Wong edan nulya waras
Kidung adalah doa yang dituangkan ke dalam sastra, baik puisi atau macapat. Tidak selamanya kidung ditembangkan, ada kalanya dibaca. Kidung juga hasil karya sastra zaman Jawa pertengahan (Majapahit akhir) menggunakan bahasa Jawa tengahan, bentuknya tembang, baik nama maupun metrum yang dianut seperti halnya tembang kidung. Dibandingkan dengan serat kakawin, kidung sangatlah berbeda dengan kakawin (karya sastra Jawa kuno), kakawin merupakan karya sastra Jawa kuno yang mendapat pengaruh dari India, sedangkan kidung asli Jawa tidak mengenal istilah guru dan lagu (suara panjang dan pendek) Walaupun seperti macapat, tetapi metrum kidung belum seketat macapat.

Begitu banyak hal yang dapat diamati dari keberadaan kidung Rahayu. Akan tetapi, melihat banyaknya permasalahan yang ada dalam penelitian ini akan lebih ditekankan pada beberapa hal yang berkaitan dengan kidung Rahayu, yaitu akan mendeskripsikan dan menganalisis bagaimana kidung Rahayu, bagaimana deskripsi leksikon yang mencerminkan konsep hidup rahayu dalam kidung Rahayu, bagaimana cermin konsep hidup orang jawa di Cikedunglor dilihat darikidung Rahayu yang digunakan, dan bagaimana klasifikasi struktur teks kidung Rahayu Cikedunglor. Penelitian ini dapat memberikan gambaran kepada masyarakat jawa khususnya di desa Cikedunglor akan pentingnya nilai-nilai yang terkandung dalam kidung Rahayu tersebut. Inilah yang menjadikan penelitian ini menarik dan penting untuk dilakukan sebagai bentuk pelestarian kebudayaan yang ada di Indonesia khususnya di Pulau Jawa. 


\section{SIMPULAN}

Islam dan Budaya Indramayu dari sisi keberagamaan pola kehidupan komunitas etnik. Deskripsi tentang budaya Indramayu yang dibatasi dalam fokus kajian kekhasan, keunikan, stereotipikal, dan stigma etnografi diharapkan mampu memberi kejernihan, kecermatan, ketepatan, kecerahan, dan kecerdasan pola pandang bagi warga-bangsa untuk membagun kebersamaan dalam keanekaragaman dalam suasana damai, tertib, dan sejahtera. Semoga artikel ringkas ini memberi manfaat.

Kidung merupakan teks lagumantra yang dinyanyikan atau syair yang dinyanyikan yang populer di masyarakat, khususnya masyarakat Jawa. Kidung ini sangat populer di daerah Cirebon-Indramayu, begitu pun masyarakat Indramayu yang ada di Desa Cikedunglor, Kecamatan Indramayu. Kidung Rahayu biasanya digunakan untuk keperluan keselamatan dari gangguan roh-roh jahat. Mereka mengenal kidung sebagai salah satu kepercayaan kejawen dan berpandangan bahwa seluruh hidup dan kehidupan berasal dari Gusti Sikang Sawiji-wiji (Tuhan yang Inti dari Segala Inti) atau Gusti Nu Maha Tunggal (Tuhan yang Maha Esa).

Kidung Rahayu memiliki struktur katayang tidak sesuai dengan kaidah sintaksis, seperti penggunaan huruf besar atau huruf kecil yang selalu digunakan pada setiap awal larik yang tidak disertai dengan tanda titik diakhir larik. Secara sintaksis, kidung Rahayu tidak memiliki fungsi yang beraturan dan tidak memiliki peran disetiap lariknya. Kategori pada kidung Rahayu didominasi oleh kategori nomina. Hal tersebut disebabkan larik kidung Rahayu menggunakan benda sebagai ungkapan. Selanjutnya pada analisis tema terdapat macam-macam isotopi, diantaranya: ketuhanan, pemberian, waktu, kegiatan, manusia, perasaan, kenikmatan, kekuatan, benda, persepsi pancaindera. Sementara itu, analisis referensi leksikon dalam kidung Rahayu di Desa Cikedunglor dapat digolongkan menjadi bermacam-macam, yakni: (1) permohonan, (2) manusia, (3) bagian tubuh, (4) waktu, (5) tempat, (6) aktivitas, (7) keadaan, (8) alam, (9) benda, (10) ketuhanan, dan (11) harapan.

Pada tataran pencerminan mengenai konsep hidup rahayu orang Jawa di Desa Cikedunglor dapat dideskripsikan oleh kalimat berikut (1-63) Dadiya sarirahayu 'anda menjadi selamat' dan dari keseluruhananalisis data, bahwa gambarankonsep hidup rahayu menurut orang Jawa di Cikedunglor dapat dilihat dari kalimat-kalimat dan leksikon yang terdapat dalam kidung Rahayu.

\section{DAFTAR PUSTAKA}

Alwi, Hasan. 2001. Kamus Besar Bahasa Indonesia. Ed. III. Jakarta: Depdiknas RI dan Balai Pustaka.

Azra, Azumardi. 1999. Konteks Berteologi di Indonesia: Pengalaman Islam. Cet. I. Jakarta: Paramadina.

Chaer, Abdul. (2007). Linguistik Umum. Jakarta: Rineka Cipta.

Departemen Pendidikan Nasional. (2008). Kamus Besar Bahasa Indonesia EdisiKeempat. Jakarta: Gramedia.

Duranti, Alessandro. (1997). Linguistic Anthropology. Cambridge: Cambridge University Press.

Duranti, Alessandro. (2004). A Companion to Linguistic Anthropology. Australia:

Blackwell Publishing Ltd.

Eriyanto. (2001). Analisis Wacana: Pengantar Analisis Teks Media.Yogyakarta. LKIS 
Foley, William A. (2001). Anthropological Linguistics. Massachusetts: Balckwell Publisher Inc.

Geertz, Clifford.(1981) Abangan, Santri, Priyayidalam Masyaraka Jawa. Jakarta: Pustaka Jaya.

Glaser, N \& Moynihan, DP (Eds.) 1981. Etnicity: Theory and Experience. Cambridge: Harvard University Press.

Herusatoto, Budiono. (2008). Banyumas: Sejarah, Budaya, Bahasa, dan Watak. Yogyakarta: Lkis.

Hymes, Dell. (1980). "Models of Interactions of Language and Social Life". Dalam John J. Gumperz dan Dell Hymes, eds. Direction inSociolinguistics. New York: Holt, Rinehart and Winston Inc.

Hymes, Dell. (1980). Foundations in Sociolinguistics: An Ethnograpics Approach Philadelpia: University of Pennsylvania Press.

Kasim, Supali. (2013). Budaya Dermayu. Yogyakarta: Poestakadjati.

Kasim, Supali. (2011). Menapak Jejak Sejarah Indramayu. Yogyakarta: Frame publishing.

Koentjaraningrat. (1981). Metode-Metode Penelitian Masyarakat. J a k a r ta : Gramedia.

Koentjaraningrat. (1981). Beberapa Pokok Antropologi Sosial. Jakarta: Dian Rakyat.

Koentjaraningrat (red.). (1976). Manusia dan Kebudayaan di Indonesia. Jakarta: Djambatan.

Kridalaksana, H. (2001). Kamus Linguistik. Jakarta: Gramedia Pustaka Utama.

Kridalaksana, H. (2007). Pembentukan Kata dalam Bahasa Indonesia. Jakarta: Gramedia Pustaka Utama.

Miles, M.B., \& Huberman, A.M. (1992). Analisis Data Kualitatif : Buku Sumber Tentang Metode-Metode Baru. Jakarta: UI-Press.
Moleong, L. (2000). Metodologi Penelitian Kualitatif. Bandung: Remaja Rosdakarya.

MPSS, Pudentia, peny. (1998). Metodologi Kajian Tradisi LisanJakarta:Yayasan Obor Indonesia.

Nuryani. (2010). Wacana Ritual Selamatan di Pasarean Gunung Kawi MalangJawa Timur: Kajian Linguistik Antropologis. Disertasi pada Fakultas IlmuBudaya Universitas Gadjah Mada Yogyakarta.

Pusat Bahasa. (2001). KamusBesarBahasa Indonesia. Jakarta: Balai Pustaka

Ramlan, M. (2001). Ilmu Bahasa Indonesia: Sintaksis. Yogyakarta: CV Karyono.

Ratna, Nyoman Kutha. (2011). Estetika Sastra dan Budaya. Yogyakarta: Pustaka Pelajar.

Rahman, Fazlur. 1999. Islam and Modernity: Transformation of an Intellectual Tradition Chicago; The university of Chicago Press

Sibarani, Robert. (2004). Antropolinguistik. Antropologi Linguistik, Linguistik Antropologi. Medan: Poda.

Sitaresmi, N.\& MahmudF. (2011). Pengantar Semantik Bahasa Indonesia. Bandung: UPI Press.

Soedjijono, Kusnadi Adi Wiryawan, \& Imam Hanafi. (1987). Struktur dan IsiMantra Bahasa Jawa Di Jawa Timur. Jakarta: Departemen Pendidikan danKebudayaan.

Sudaryanto. (1998). Metode Linguistik Bagian Kedua: Metode dan Aneka Teknik Pengumpulan Data. Yogyakarta: Duta Wacana University Press.

Warnaen, Suwarsih dkk. (1987). Pandangan Hidup Orang Sunda: SepertiTercermin dalam Tradisi Lisan dan Sastra Sunda. Bandung: Bagian Proyek Penelitian dan Pengkajian Kebudayaan Sunda (Sundalogi), 
Direktorat Jendral Kebudayaan, Departemen Pendidikan dan Kebudayaan.

Wiyata, A. Latief. 2002. Carok; Konflik Kekerasan dan Harga Diri Orang Indramayu. Yogyakarta: LKiS.

Wiyata, A. Latief. 2003. Indramayu yang Patuh?; Kajian Antropologi Mengenai Budaya Indramayu. Jakarta: CERIC-FISIP UI.

\section{Sumber Internet}

Astro, Masuki M. 2006. orang Indramayu peramah yang Sering Dikonotasikan Negatif. (http://www.mamboteam. com) diakses 4 November 2006.
Wiyata, A. Latief. 2005. Model Rekonsiliasi Orang Indramayu. (http://www.fisip. ui. edu/ceric) diakses 16 Agustus 2006.

\section{HASIL DISKUSI}

Tidak ada pertanyaan 